\title{
Open Versus Percutaneous Approach of Renal Tumor Biopsy at Cipto Mangunkusumo Hospital: A Single-center Experience
}

\author{
Luki Ertandri $^{1 *}$, Agus Rizal A. H. Hamid ${ }^{1}$, Meilania Saraswati ${ }^{2}$, Chaidir A. Mochtar $^{1}$, Rainy Umbas ${ }^{1}$ (D) \\ ${ }^{1}$ Department of Urology, Medical Faculty, Universitas Indonesia, Cipto Mangunkusumo General Hospital, Jakarta, Indonesia; \\ ${ }^{2}$ Department of Pathology Anatomy, Medical Faculty, Universitas Indonesia, Cipto Mangunkusumo General Hospital, Jakarta, \\ Indonesia
}

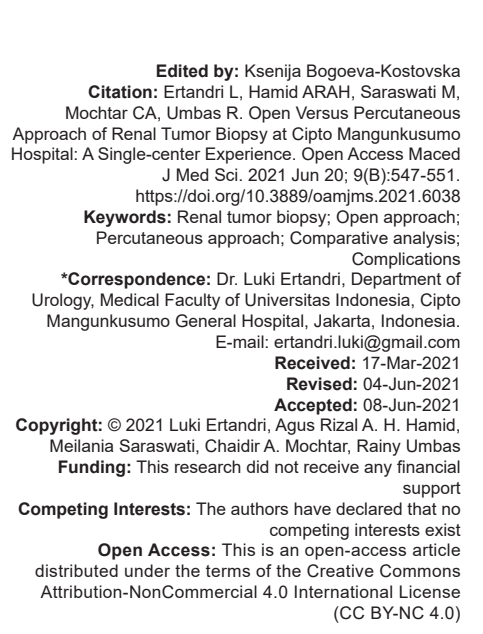

\begin{abstract}
BACKGROUND: Renal tumor biopsy is beneficial as it is capable of distinguishing between histological types of renal tumor; hence, it plays an important role in deciding the best therapy regimen.

AIM: This study aims to evaluate the clinical experiences of renal biopsy in Cipto Mangunkusumo National Referra Hospital (RSCM), with both a percutaneous and open approach. It also aims to analyze the indications, results, intraoperative information, and complications of the two approaches.

METHODS: This study was conducted using the retrospective cohort design; meanwhile, data were collected from RSCM from 1990 to 2019. The biopsy sample was taken using percutaneous and open renal biopsy, while comparative analysis was done between the two biopsy approaches.

RESULTS: Data were collected from 33 patients that underwent renal biopsy from 1990 to 2019. Majority of the cases were diagnosed as unresectable renal tumor, while histological examination found clear cell carcinoma in mos of the cases $(73 \%)$. Furthermore, the open approach showed longer duration and higher blood loss compared to percutaneous technique with median $60(30-120)$ versus $30(5-60)$ min $(p<0.001)$ and $100(5-650)$ versus $2(1-5)$ $\mathrm{ml}(\mathrm{p}<0.001)$, respectively. In general, complications were reported to be low for both techniques.

CONCLUSION: Based on the results, percutaneous renal biopsy has similar efficacy and complications rates in tumor sampling for histopathology together with open approach. However, there were significant differences in the duration and blood loss; hence, percutaneous biopsy is more favorable.
\end{abstract}

\section{Introduction}

Renal tumors constitute one of the most common type of cancer, it ranked $9^{\text {th }}$ in men and $14^{\text {th }}$ in women worldwide and covered about $4,00,000$ new cases in 2018 [1]. The incidence is reportedly increasing over time, thereby making it a significant problem in urology practice [1]. In Indonesia, the overall incidence of kidney cancer is estimated to be 0.84 cases per 1,00,000 population from the GLOBOCAN 2018 data [2]. The disease is histologically heterogeneous and different histological subtypes are associated with a difference in prognosis, risk of metastases, causespecific survival, and recurrence rate [3]. Furthermore, metastases cases portend poor prognosis with $8.2 \%$ overall survival at 5 years [4]. With this condition, histological evaluation plays an important role in disease workup and evaluation for better treatment decision [5].

The use of renal tumor biopsy (RTB) is beneficial because it is capable of distinguishing between the histological types of renal tumor from the benign type [6], [7]. Furthermore, in advanced cases of the disease (stage IV or relapse), histological differentiation also plays an important role in deciding the most suitable therapy regimen [6]. Histological examination through tissue samples is mostly taken from unresectable cases. According to the guidelines for advanced renal tumor, RTB plays a significant role in providing histological information, resulting in specific treatment decision for patients [6], [7].

This study aims to evaluate the clinical experiences of RTB in Cipto Mangunkusumo Hospital (RSCM), a national referral hospital with both a percutaneous and open approach. In addition, it also aims to analyze the results, intraoperative information, and complications of the two approaches.

\section{Methods}

\section{Design and samples}

This was a descriptive study conducted using the retrospective cohort design. The data were 
collected from uro-oncology medical records and pathology anatomy database describing the profile of RTB performed at the Department of Urology in RSCM from 1990 to 2020. Besides, the total sampling method was used with a total of 33 patients that had undergone renal biopsy by the urologist in RSCM. The protocol for this study was approved by the ethics committee (KET.526/UN2.F1/ETIK/PPM.002/2020, Faculty of Medicine, University of Indonesia. Meanwhile, written informed consents for publication of clinical details were obtained from the patients.

\section{Inclusion and exclusion criteria}

The patients included in this study had undergone RTB, both percutaneous and open procedures, at the Department of Urology RSCM with available pathology anatomy results, whereas patients that were not followed up after biopsy were excluded from the study.

\section{RTB technique}

The percutaneous needle core RTB was performed using a real-time ultrasound-guided approach with local or general anesthesia depending on patients condition. The patient was positioned in a prone position depending on the difficulty of getting the tumor puncture site, usually because there is bowel or a large posterior mass. Hemostasis factors were checked normal; meanwhile, the procedure was performed by freehand technique, using a mechanized spring-loaded needle gun (Biopsy Instrument, C.R. Bard, Covington, GA) $18 \mathrm{G}$ needle or a tru-cut $16 \mathrm{G}$ needle biopsy. The needle puncture was performed with a coaxial approach on the location of the lesion upon imaging to avoid seeding. Besides, the needle core biopsy was the most predominant technique in the institution. The core was collected using a free-hand technique; meanwhile, the number of cores collected varied, depending on the patient characteristics and operators discretion. Patients were generally given prophylactic antibiotics before the procedure, while follow-up for complications was done for a day and 1 week after the procedure. The open RTB was performed in lumbotomy position under general anesthesia.

\section{Data collection}

Data were collected from 1990 to 2020 from medical records and pathology anatomy database. Patients' characteristics included age, gender, diagnosis, clinical staging, lesion side, tumor size, and indication for biopsy, pathology anatomy results, and intraoperative variables including duration, type and technique of biopsy, number of cores taken, blood loss, types of anesthesia, and antibiotic regimen as well as complications including upper urinary tracks infection (UTI), sepsis, hematuria, and blood transfusion.

\section{Data analysis}

The data were descriptively presented in the form of tables; meanwhile, a comparison between the percutaneous and open procedures with the intraoperative variables was analyzed using Mann-Whitney test for non-parametric variables and complications using Chi-square categorical test. Furthermore, the statistically significant setting was $p<0.05$. All data analysis was performed using SPSS v.23 (IBM Statistics, New York).

\section{Results}

A total of 33 patients with advanced size renal tumor (T3 and T4 stage) and had undergone RTB participated in this study. There was no small renal mass (SRM) lesion as an indication for biopsy. Moreover, the median age of the patients was 48 (1966) years, consisting of 25 males and 8 females, while the techniques used for biopsy were percutaneous (54\%) and open (46\%). The biopsy success rate in collecting representative histological information was $97 \%$.

The histological findings showed that clear cell renal cell carcinoma (RCC) had the highest number (73\%) followed by squamous RCC (15\%) and upper tract urothelial carcinoma (UTUC) (6\%). Only one case had papillary renal carcinoma histological features. One result from the percutaneous biopsy was not considered representative due to technical problems and operators error. The elaborate description of indications and histological results is shown in Table 1.

Table 1: Patients characteristics and pathology results

\begin{tabular}{ll}
\hline Variables & $\mathrm{n}=33$ \\
\hline Median age, year (min-max) & $48(19-66)$ \\
Gender (M:F) & $25: 8$ \\
Year, $\mathrm{n}(\%)$ & \\
1990-1999 & $1(3)$ \\
$2000-2009$ & $12(36)$ \\
$2010-2020$ & $20(61)$ \\
Lesion side, $\mathrm{n}(\%)$ & \\
Right & $16(48)$ \\
Left & $17(52)$ \\
Technique, $\mathrm{n}(\%)$ & \\
Percutaneous & $18(54)$ \\
Open & $15(46)$ \\
Success rate & 97 \\
Staging, $\mathrm{n}$ (\%) & \\
T3 & $6(18)$ \\
T4 & $27(82)$ \\
Median bleeding volume, ml (min-max) & $5(1-650)$ \\
Median surgery duration, minute (min-max) & $40(5-120)$ \\
Re-biopsy & None \\
Pathology anatomy results, $\mathrm{n}$ (\%) & \\
Clear cell RCC & $24(73)$ \\
Squamous RCC & $5(15)$ \\
UTUC & $2(6)$ \\
Papillary RCC & $1(3)$ \\
Not representative & $1(3)$ \\
\hline RCC: Renal cell carcinoma, UTUC: Upper tract urothelial carcinoma. &
\end{tabular}

Figure 1 showed the trend in the hospital regarding the approach utilized to obtain the sample for renal biopsy from 1990 to 2020 . It shows that the preferred technique from 1990 to 2009 was the open 


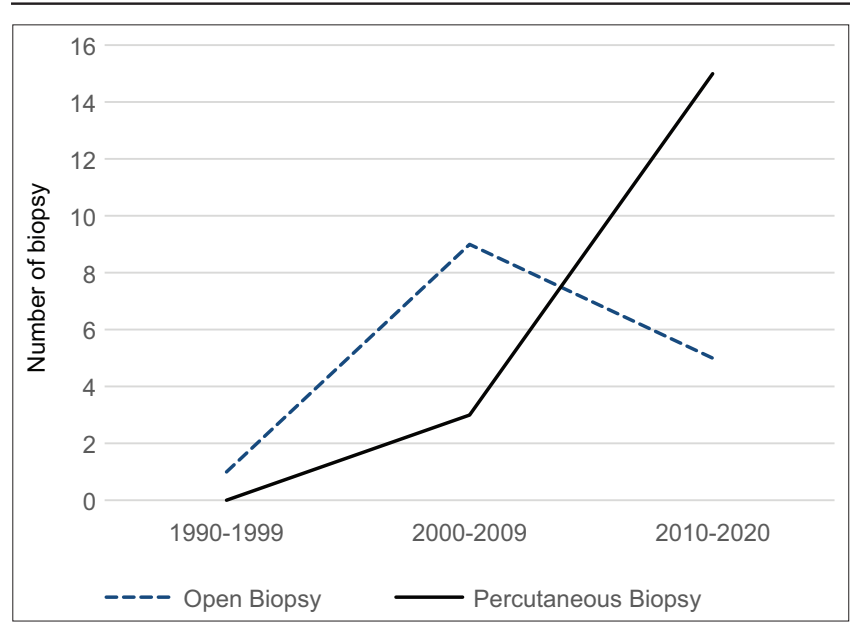

Figure 1: Renal tumor biopsy trend in Cipto Mangunkusumo Hospital from 1990 to 2020

type. However, from 2010 till now, the approach has shifted to percutaneous.

Eighteen patients underwent percutaneous RTB, while 15 underwent open renal biopsy. Intraoperative parameters showed longer duration and higher blood loss in the open approach compared to percutaneous with a median of $60(30-120)$ versus $30(5-60) \mathrm{min}$ $(p<0.001)$ and $100(5-650)$ versus $2(1-5) \mathrm{ml}(p<0.001)$, respectively. The percutaneous approach was mostly performed using local anesthesia (44\%), while the open biopsy was mostly performed using general anesthesia (93\%), although, in recent years, percutaneous biopsy has also been conducted with general anesthesia. The most used antibiotic regimen was cefoperazone sulbactam. More elaborate intraoperative parameter profile of the renal biopsy is shown in Table 2 . The overall complication rate was low; meanwhile, three complication cases were reported and no statistical difference was found between percutaneous and open renal biopsy groups.

Table 2: Intraoperative parameters of the RTB procedure

\begin{tabular}{|c|c|c|c|c|}
\hline Intraoperative parameters & $\begin{array}{l}\text { Percutaneous } \\
(\mathrm{n}=18)\end{array}$ & $\begin{array}{l}\text { Open } \\
(n=15)\end{array}$ & $\begin{array}{l}\text { Total } \\
(\mathrm{n}=33)\end{array}$ & $\mathrm{p}$ \\
\hline Median duration, minute (min-max) & $30(5-60)$ & $60(30-120)$ & $30(5-120)$ & $<0.001^{* \mathrm{a}}$ \\
\hline Median blood loss, ml (min-max) & $2(1-5)$ & $100(5-650)$ & $0(0-650)$ & $<0.001^{\star^{a}}$ \\
\hline \multicolumn{5}{|l|}{ Anesthesia method, $\mathrm{n}(\%)$} \\
\hline Local & $8(44)$ & $1(7)$ & $9(27)$ & \multirow[t]{3}{*}{$0.030^{\mathrm{a}}$} \\
\hline Spinal & $3(17)$ & 0 & $3(9)$ & \\
\hline General & $7(39)$ & $14(93)$ & $21(64)$ & \\
\hline \multicolumn{5}{|l|}{ Antibiotics, n (\%) } \\
\hline Cefoperazone sulbactam & $16(88.88)$ & $9(60)$ & $25(76)$ & \multirow[t]{2}{*}{$0.230^{\mathrm{a}}$} \\
\hline Ceftriaxone & $2(11.22)$ & $6(40)$ & $8(24)$ & \\
\hline \multicolumn{5}{|l|}{ Complications, n (\%) } \\
\hline Prolonged pain & 0 & $1(7)$ & $1(3)$ & $0.321^{b}$ \\
\hline Hematuria & $1(6)$ & $1(7)$ & $2(6)$ & $1.000^{\mathrm{b}}$ \\
\hline Transfusion & 0 & 0 & 0 & N/A \\
\hline UTI & 0 & 0 & 0 & $\mathrm{~N} / \mathrm{A}$ \\
\hline Sepsis & 0 & 0 & 0 & N/A \\
\hline
\end{tabular}

UTI. Urinary tracks infection.

\section{Discussion}

The clinical application of RTB for renal masses has shifted over the years [8], [9]. RTB is primarily used for SRM but might also be indicated for larger masses or even metastatic states. It is also used to determine treatment options by identifying the results of the biopsy and to confirm success after ablation modality. Approximately $2-5 \%$ of SRM is metastatic, which has different management compared to renal malignancies [10]. Two major approaches were used for renal biopsy, namely percutaneous and open biopsy. In the percutaneous biopsy procedure, a small needle is inserted to the previous incision to obtain the targeted tissue sample [10].

Based on the results, the trend of RTB is growing over the years in RCSM. The number of patients that underwent RTB using the percutaneous approach has significantly increased over the past decades compared to open. However, this was contrary to previous studies in which most of the patients reportedly underwent RTB before the incidental discovery of tumor masses or in few cases due to SRM [11], [12]. All patients underwent RTB because of unresectable tumor masses. This is because the center is a tertiary healthcare facility, where most of the patients were diagnosed or referred. Furthermore, the rationale to conduct renal biopsy in this stage was to identify the histological features of the renal tumor and establish suitable treatment for each patient. In the advance disease cases (unresectable or recurring), histological information obtained through renal biopsy plays an important role in the process of deciding the most suitable treatment [6]. Following the guidelines for advanced stages of renal tumors, biopsy plays an important role in providing histological information on the disease to provide specific treatment to patients [6], [7].

The results showed a total of 33 patients with adequate intra-operative information from the medical records within a 30-year period consisting of 18-15 patients with percutaneous and open biopsy, respectively. A previous study suggested that RTB using the percutaneous approach has safety risk, high diagnostics sensitivity, and specificity; it is also capable of distinguishing between tumor histologic subtypes and nuclear grade [13]. However, current renal biopsy approaches have been associated with high safety, low risk of seeding, and high accuracy in differentiating histological subtypes; hence, it is able to differentiate patients' prognosis. Notwithstanding, a recent metaanalysis by Marconi et al. showed different results [14]. Based on the results, the diagnostic rate of RTB was $92 \%$, while the sensitivity and specificity of core biopsy were $99.1-93.2 \%$, respectively. This is similar to the results obtained in this study, where the overall success of RTB was $97 \%$ and there was no re-biopsy conducted throughout the cohort.

The patients' median age was 48 (19-6) years consisting of 25 males and 8 females. Besides, the number of cases reached its peak during 2010-2020 $(60.6 \%)$. Based on previous studies, older age and men were associated with poor prognosis [12], [14]. Similar to 
the results obtained in this study, majority of the cases were unresectable tumor mass in male with older age [15].

The histological results showed that the largest number of histological diagnosis were clear cell RCC $(73 \%)$ followed by squamous cell (15\%) and UTUC (6\%). The number of malignancy cases reported in this study was in line with 18 years long study conducted by Rabbani et al., where a number of 34 patients with malignancy were described in relation to the histopathological results [15], [16]. Moreover, aside smaller tumors, the larger unresectable tumors in this study are not at risk of failure, this is in line with results from other studies [17], [18].

There were significant differences in duration and blood loss between the two approaches; based on results, the percutaneous biopsy is more favorable. Although no direct comparison has ever been made on percutaneous and open RTB, the median of each type was similar to results from previously published studies. There were few patients in the percutaneous group that had general anesthesia due to personal requests or specific health conditions. However, in recent years, majority of percutaneous renal biopsies were conducted under general anesthesia in the hospital.

Contraindication for RTB was coagulopathy and cases in which the result of tissue biopsy failed to improve or change therapy. Biopsy is not performed on patients diagnosed through imaging modality due to the high positive predictive value; hence, even when the biopsy result is found to be negative, it is still unable to change the therapy [19].

There are only a few reports of complications from RTB; however, the several cases reported in some literature include bleeding and fistula incidents. In a recent systematic review, complications that occurred in $<5 \%$ of the population included hematoma, pain, hematuria, pneumothorax, and bleeding. The complication rate in this study was considerably low. Although not significantly different, open renal biopsy showed a higher complication rate (14\%). The notable complications include prolonged pain and hematuria in relatively few patients; meanwhile, there were no cases of UTI, transfusion, and sepsis [10], [20].

The major limitation of this study was the small number of patients enrolled. From a study period of 30 years, 33 patients were reported to have a renal biopsy with sufficient histopathological reports. Furthermore, given that the study used a descriptive approach, the comparison between the types of biopsy used in this study was not analyzed.

\section{Conclusion}

Based on the results, percutaneous renal biopsy have similar efficacy in tumor sampling for histopathology together with an open approach. Meanwhile, there are significant differences in the procedure duration and blood loss between both approaches; hence, a percutaneous biopsy is more favorable. In addition, complication rates are considerably low, with no statistically significant difference between percutaneous and open biopsy.

\section{References}

1. Ghali F, Patel SH, Derweesh IH. Current status of immunotherapy for localized and locally advanced renal cell carcinoma. J Oncol. 2019;2019:7309205. https://doi.org/10.1155/2019/7309205 PMid:31057615

2. Bray F, Ferlay J, Soerjomataram I, Siegel RL, Torre LA, Jemal A. Global cancer statistics 2018: GLOBOCAN estimates of incidence and mortality worldwide for 36 cancers in 185 countries. CA Cancer J Clin. 2018;68(6):394-24. https://doi. org/10.3322/caac.21492

PMid:30207593

3. Ozur Y, Saadettin E, Erdem K, Bulent S, Cagatay G, Taner D, et al. A preoperative prognostic model predicting recurrencefree survival for patients with kidney cancer. Jpn J Clin Oncol. 2013;43(1):63-6.

PMid:23159766

4. Tsimafayeu I, Zolotareva T, Varlamo S, Zukov R, Petkau V, Masbich M. Five-year survival of patients with metastatic renal cell carcinoma in the russian federation: Results from the RENSUR5 registry. Clin Genitourin Cancer. 2017;15:e1069-72. https://doi.org/10.1016/j.clgc.2017.07.017

PMid:28882737

5. Muglia VF, Prando A. Renal cell carcinoma: Histological classification and correlation with imaging findings. Radiol Bras. 2015;48(3):166-74. https://doi. org/10.1590/0100-3984.2013.1927

PMid:26185343

6. NCCN CLinical Practice Guidelines in Oncology: Kidney Cancer National Comprehensive Cancer Network; 2019.

7. Ljunberg B, Albiges K, Bensalah K, Bex A, Giles RH, Hora M, et al. Renal cell carcinoma: EAU guidelines. Eur Urol. 2019; 75(5):799-810

8. Tomaszewski JJ, Uzzo RG, Smaldone MC. Heterogeneity and renal mass biopsy: A review of its role and reliability. Cancer Biol Med. 2014;11(3):162-72

PMid:25364577

9. Luciano RL, Moeckel GW. Update on the native kidney biopsy: Core curriculum. Am J Kidney Dis. 2019;73(3):404-15. https:// doi.org/10.1053/j.ajkd.2018.10.011 PMid:30661724

10. Herrera-Caceres JO, Finelli A, Jewett MA. Renal Tumor Biopsy: Indicators, Technique, Safety, Accuracy Results, and Impact on Treatment Decision Management. World J Urol. 2019;37(3):43743. https://doi.org/10.1007/s00345-018-2373-9 PMid:30022406

11. Richard PO, Jewett MA, Bhatt JR, Kachura JR, Evans AJ, Zlotta $A R$, et al. Renal tumor biopsy for small renal masses: A singlecenter 13-year experience. Eur Urol. 2015;68:1007-13. https:// doi.org/10.1016/j.eururo.2015.04.004

PMid:25900781

12. Shannon BA, Cohen RJ, de Bruto $H$, Davies RJ. The value 
of preoperative needle core biopsy for diagnosing benign lesions among small, incidentally detected renal masses. J Urol. 2008;180(4):1257-61. https://doi.org/10.1016/j. juro.2008.12.009

PMid:18707712

13. Volpe A, Finelli A, Gill IS, Jewett MA, Martignoni G, Polascik TJ, et al. Rationale for percutaneous biopsy and histologic characterisation of renal tumours. Eur Urol. 2012;62(3):491504. https://doi.org/10.1016/j.eururo.2012.05.009

14. Marconi L, Dabestani S, Lam TB, Hofmann F, Stewart F, Norrie J, et al. Systematic review and meta-analysis of diagnostic accuracy of percutaneous renal tumour biopsy. Eur Urol. 2016;69(4):66073. https://doi.org/10.1016/j.eururo.2015.12.043 PMid:26323946

15. Rabbani MA, Memon GM, Ahmad B, Memon S, Tahir SA, Thir S. Percutaneous renal biopsy results: A retrospective analysis of 511 consecutive cases. Saudi J Kidney Dis Transpl. 2012;23(3):614-8.

PMid:22569458

16. Ha SB, Kwak C. Current status of renal biopsy for small renal masses. Korean J Urol. 2014;55(9):568-73. https://doi. org/10.4111/kju.2014.55.9.568

PMid:25237457

17. Leveridge MJ, Finelli A, Kachura JR, Evans A, Chung $H$, Shiff DA, et al. Outcomes of small renal mass needle core biopsy, nondiagnostic percutaneous biopsy, and the role of repeat biopsy. Eur Urol. 2011;60(3):578-84. https://doi.org/10.1016/j. eururo.2011.06.021

PMid:21704449

18. Miyake M, Fukui S, Gotoh D, Matsumura Y, Samma S, Matsumoto $\mathrm{Y}$, et al. The diagnostic utility of retroperitoneoscopic tissue biopsy for unresectable retroperitoneal lesions excluding urogenital cancers. World J Surg Oncol. 2019;17(1):35. https:// doi.org/10.1186/s12957-019-1581-0

PMid:30777073

19. Hamid AR, et al. Pedoman Tata Laksana Kanker Ginjal. $2^{\text {th }}$ ed Indonesia: Penerbit Ikatan Ahli Urologi Indonesia; 2019.

20. Stec AA, Stratton KL, Kaufman MR, Chang SS, Milam DF, Herrell SD, et al. Open renal biopsy: Comorbidities and complications ina contemporaryseries. BJUInt. 2010;106(1):1026. https://doi.org/10.1111/j.1464-410x.2009.09015.x PMid:19874299 